\title{
Multi-Grade Teaching and Inclusion: Selected Cases in the Free State Province of South Africa
}

\author{
T.M. Makoelle* and M.J. Malindi** \\ Department of Educational Psychology, University of Johannesburg, South Africa \\ E-mail: "<tmakoelle@uj.ac.za>, ${ }^{* *}<$ mmalindi@uj.ac.za $>$
}

KEYWORDS Inclusion. Inclusive Pedagogy. Integration. Mainstreaming. Multi-grade Teaching

\begin{abstract}
Multi-grade teaching is a commonly used pedagogic strategy in rural schools. However, this form of teaching continues to present challenges to both the teacher and the learner in particular since the advent of inclusive education in South Africa. The policy on inclusive education is silent on how it could be enhanced in a multi-grade class. This paper therefore attempts to analyse and deconstruct the tensions, contradictions and anomalies within the practice of inclusion as a pedagogic discourse in a multi-grade teaching system. The qualitative study on which this article is based employed a critical emancipatory lens and critical realist analysis as instruments with which to analyse narratives from selected cases at multi-grade schools in the Free State province of South Africa. The findings of the study indicated that, while the knowledge and skills teachers need to enhance inclusion within a multi-graded system were limited, well-designed teaching practices in a multi-grade class may enhance an inclusive pedagogy and promote inclusive learning.
\end{abstract}

\section{INTRODUCTION}

There is a global movement towards accommodating learners with special educational needs in regular classrooms. The Department of Education in South Africa has made it clear that special education as it existed in the past will be replaced with an inclusive model of education in line with international developments (Makoelle 2014). This includes schools with multi-grade classrooms, especially in rural areas. The increase in the number of learners requiring specialised education and the implementation of inclusive education have become a global agenda. Inclusive education looks at how all learners, regardless of their individual differences, could be taught in regular mainstream school classrooms (Makoelle 2013). The first challenge facing the theory or ideology of inclusion is the on-going debate about how this can be achieved. Trends have emerged from what is termed integration as opposed to full inclusion, as explained in the following quotation:

"All forms of integration assume some type of assimilation of the disabled learners into the mainstream school largely unchanged. Inclusion is not a static state like integration. It is a continuing process of school ethos and change. It is about building school community that accepts and value differences” (Florian 2007: 37)

Therefore, simply placing learners in a mainstream school without adequate measures to respond to their needs is contrary to the ideal of full inclusion. In this regard, Ainscow and Far- rell (2002) distinguish between integration and inclusion by referring to integration as the placement of learners in terms of three broad approaches:

- Location: classes are located within the mainstream campus.

- Social interaction: learners meet and interact during social activities at schools, for example at meal times.

- Functionality: learners with difficulties are placed in the mainstream classes alongside their peers.

Inclusion, according to the latter approach, means that learners should be welcomed as full members of the class regardless of their differences (Ainscow 2013). In South Africa, inclusion and integration were clearly spelled out in White Paper 6 (DoE 2001: 17) on education. Table 1 illustrates the differences between the two are approaches.

The emphasis in White Paper 6 (DoE: 2001) is on the significance of support that should be provided to all learners rather than focusing on individuals. Given the challenge of operationalising inclusion in the classroom, lessons can be drawn from the definition of inclusive education by UNESCO (2001) in an attempt to arrive at a common understanding. The main features of the definition of inclusive education include the following:

Inclusive education:

- acknowledges that all children can learn and that all need some form of support for learning; 
Table 1: Essential differences between mainstreaming and inclusion

\begin{tabular}{ll}
\hline Mainstreaming or integration & Inclusion \\
\hline $\begin{array}{l}\text { Mainstreaming is about getting learners to "fit into" a } \\
\text { particular kind of system, or integrating them into the } \\
\text { existing system. }\end{array}$ & $\begin{array}{l}\text { Inclusion is about recognising and respecting the } \\
\text { differences among all learners and building on the } \\
\text { similarities. }\end{array}$ \\
$\begin{array}{l}\text { Mainstreaming is about giving some learners extra } \\
\text { the normal classroom routines. Learners are assessed } \\
\text { by specialists who diagnose and prescribe technical } \\
\text { interventions, such as the placement of learners in } \\
\text { special programmes. }\end{array}$ & $\begin{array}{l}\text { Inclusion is about supporting all learners, educators and } \\
\text { needs can be met. The focus is on the teaching and } \\
\text { learning actors, with the emphasis on the development } \\
\text { of good teaching strategies that will be of benefit to all } \\
\text { learners. }\end{array}$ \\
$\begin{array}{ll}\text { Mainstreaming and integration focus on changes that the place in learners so that they can "fit in" } \\
\text { Inclusion focuses on overcoming barriers in the system } \\
\text { that prevent it from meeting the full range of learning } \\
\text { needs. The focus is on the adaptation of and support } \\
\text { system available in the classroom. }\end{array}$ \\
\hline
\end{tabular}

- aims to uncover and minimise barriers to learning;

- is broader than formal schooling and includes the home community and other opportunities for education outside the school;

- is about changing attitudes, behaviour, teaching methods, the curriculum, and the environment to meet the needs of all children;

- is a dynamic process which is constantly evolving according to local cultures and contexts and part of the world strategy to promote an inclusive society.

Dyson and Millward (2000: 64) define inclusive education in similar terms as follows:

Inclusive education means education that is non-discriminatory in terms of disability, culture, gender or other aspects of student or staff that are assigned significance by the society. It involves all students in a community with no exceptions and irrespective of their intellectual, physical, sensory or other differences having equal rights to access the culturally valued curriculum of their society as full-time valued members of age appropriate mainstream classrooms. Inclusion emphasizes diversity over assimilation, strives to avoid the colonization of minority experiences by the dominant modes of thought and action.

The UNESCO understanding of inclusion seems to converge with the definition by Dyson and Millward (2000) in the sense that in both instances prominence is given to aspects such as notions of equality, access and provision of education to all, regardless of their background, and a curriculum responsive to the needs of all learners. These aspects seem to inform definitions of inclusive education across the world despite the varied and diverse conceptualisations referred to earlier.

The South African definition of inclusive education embraces similar sentiments. White Paper 6 (DoE 2001) states that inclusive education is about:

- acknowledging that all children and the youth can learn and that they all need support;

- accepting and respecting the fact that all learners are different in some way and have different learning needs which are equally valued as an ordinary part of human experience;

- enabling education structures, systems and learning methodologies to meet the needs of all learners;

- acknowledging and respecting differences between learners, whether due to age, gender, ethnicity, class, disability or HIV status;

- acknowledging that inclusive education is broader than formal schooling and that it also occurs in the home and community, as well as within formal and informal modes and structures;

- changing attitudes, behaviour, teaching methodologies, curricula and the environment to meet the needs of all learners;

- maximising the participation of all learners in the culture and the curricula of educational institutions;

- uncovering and minimising barriers to learning and empowering learners by developing their strengths and enabling them to participate critically in the process of learning. 
The general understanding of inclusion is that all learners are included within the mainstream classroom and that support is given to all learners in response to their needs (Makoelle 2013).

However, despite all the principles enshrined in the policy, there is still the conundrum of translating them into practice and giving them the form and structure of an inclusive pedagogy. Corbett (2001) defines inclusive pedagogy as an approach intended to promote the culture of accommodating all by making use of diverse teaching strategies in the classroom. It is associated with a connective pedagogy; that is, first connecting learners with their own learning and then connecting their learning to the curriculum (Corbett 2001). Nilholm and Alm (2010) postulate that inclusive pedagogy is a process whereby learners constantly engage with the learning material, drawing on their experiences. The material is presented as close to reality as possible and the learners are not passive recipients of knowledge but allowed to attach subjective meaning to it. However, in the research on which this article is based, inclusive pedagogy was assumed to refer to the totality of thoughts, approaches, methods, beliefs and conceptions about teaching (Makoelle 2013). This line of thinking therefore led to the posing of the following questions:

Which pedagogic practices would be relevant to and appropriate for a multi-grade classroom? When is teaching inclusive in a multigrade class, and when is it not?

Teaching as an integral aspect of pedagogy and largely determines the pedagogic approach; hence, it is important to conceptualise the phenomenon of inclusive teaching. Hart (1996) argues that inclusion is an exercise in creativity and innovation on part of the teacher. This is underscored by the manner in which Ainscow and Booth (2002), in the Index for Inclusion (dimension C: 78), conceptualise the indicators that are important in determining the characteristics of inclusive teaching. This form of teaching is planned with the instruction of all learners in mind:

- The lessons encourage the participation of all students.

- The learners are actively involved in their own learning and work collaboratively.

- Assessment contributes to the success of all learners.
- Classroom discipline is based on mutual respect.

- Teachers plan, teach and review in partnership.

- Teaching assistants support the learning and participation of all the learners.

- Homework contributes to the learning experience of everyone.

- All learners take part in activities outside the classroom.

In all the other dimensions, the Index indicates other aspects of inclusion, such as establishing inclusive values, support for diversity, and the collaboration of staff members (Rahaman and Sutherland 2011). The above description points to the cornerstone of inclusive teaching - that is, the way it responds to the needs of all learners, the way all learners are accommodated in the classroom, and how learning material is planned to encourage diversity and differentiation.

Therefore innovative thinking, which is the way teachers respond intuitively to the needs of learners in the classroom, appears to be significant. Pedagogy assumes an interactive mode: the teacher interacts with the learners during the teaching process, makes connections, builds interactive relationships between him-/herself and the learners, and fosters collaboration (Nind and Sheehy 2004; Florian and Linklater 2010; Makoelle 2013). On the other hand, inclusive teaching is associated with what Skidmore (2004) refers to as pedagogical discourses. Two distinct discourses are differentiated, namely the discourse of deviance and that of inclusion.

Elaborating on the discourse of inclusion, Skidmore (2004) seeks to clarify the notion of inclusive teaching by articulating the significance of curriculum delivery, form and content. Skidmore (2004) emphasises that the curriculum should be responsive to the needs of all learners to enhance their participation in the teaching and learning process. The author cautions against the discourse of deviance, which places more emphasis on the learners' weaknesses rather than on the teaching and support system, which could have a severely negative effect on what inclusive teaching advocates.

While it is important to conceptualise inclusive teaching, it must be remembered that it does not take place in a vacuum, and that the space and the environment in which it occurs show certain attributes and characteristics. Concep- 
tualising an inclusive class is daunting. In the past, special classrooms were designed for learners with special educational needs. The main problem was that such learners were not be living in their own world after schooling, so it did not make sense to separate them from their peers. The inclusive classroom is understood to be a place where communities of learners from different backgrounds are developed (Stainback and Stainback 1992; Volts et al. 2010). For instance, an inclusive classroom is perceived to be heterogeneously organised; support is given to all learners; diversity is valued; the teaching and curriculum are responsive to the needs of all learners; and the learners are encouraged to work together and support one another (Stainback and Stainback 1992; Makoelle 2014).

While it could be argued that all attributes centre on the need for learners to be supported, and that everyone in the classroom should participate and co-operate, it is also important to describe an inclusive classroom as more concerned with aspects such as learner composition. The following quotation gives a hypothetical thumbnail sketch of an inclusive classroom:

You are teaching a year 3 class in a regular school. Typical students in your class include two very able students (probably gifted and talented), a group of five students who can easily complete all assigned tasks, a core of fifteen "average students” who can usually complete assigned tasks with little assistance, six students with learning difficulties who struggle with all tasks and need constant teacher assistance, one student with a learning disability who cannot read but is "average" in other subjects areas, and one slow-learning student who has a mild intellectual disability and generally needs teacher assistance in all subject areas. Of these students in this "typical” class, two exhibit behaviour problems such as non-conformity and aggressive behaviour to their peers, three are boisterous to the extent of unsettling the class, three come from homes where English is a second language, and ten are from single-parent homes (Night 1999: 3).

The quotation sums up how others view an inclusive class in which the leaners are categorised according to their perceived needs and traits. While some researchers believe that all learners have educational needs, others believe that an inclusive classroom becomes a place where both learners and teachers act as their own resources (Ainscow 1999; Miles and Ainscow 2010). Encouraging learner participation is to a large extent influenced by how well human resources in particular are managed in the classroom. It is important for teachers to draw support from one another by working collaboratively in response to the needs of the learners in the classroom. However, the decision to enhance inclusion in the classroom depends to some extent on the teachers' attitudes, opinions, beliefs and willingness to implement inclusion (Tembo and Ainscow 2001; Makoelle 2013).

An inclusive class may also to some extent be conceptualised according to the activities taking place in the classroom. For instance, in an inclusive class, learner participation is pivotal; therefore, it should be emphasised that learners have to be in charge of their own learning, learn at their own pace and style, and should express their feelings about their own learning (Cheminias 2004; Makoelle 2013). The inclusive classroom should be a relatively unrestrictive learning space where learners are free to explore the alternative possibilities in their own learning. The climate in the inclusive classroom should foster emotional discipline in learners, who should be able to analyse their own strengths and weaknesses, engage in proper decision-making, be assertive and be able to resolve conflicts (Cheminias 2004). An inclusive classroom should attempt to enhance the selfconcept and self-esteem of learners so that they feel worthy of being members of the class.

Furthermore, an inclusive class can be viewed from the point of view of socialisation. For example, while teachers are responsible for making sure that an inclusive classroom is indeed a place where all learners are welcome (Lehohla and Hlalele 2012), teachers face challenges in maintaining an inclusive classroom, especially at secondary-school level (Mastropieri and Scruggs 2001). It is therefore important to consider the socialisation role of the classroom within an inclusive context.

For instance, teachers and learners are social beings who constantly interact and form relationships with one another. The promotion of inclusion in the classroom makes such relationships pivotal because they are the building blocks of an inclusive culture characterised by acceptance of and respect for others. The relationships are usually based on shared values and on recognising diversity in the classroom. 
Teachers have a responsibility to nurture relationships based on trust, but how?

The relationship between the learner and the teacher should be based on trust and mutuality. To foster caring and supportive relationships in the classroom, teachers have to ensure that they know their learners and that the learners know them, listen actively to the learners, allow them to share their views in the classroom, recognise their successes and ensure that disciplinary measures are in keeping with the maintenance of the learner's dignity and respect (Bartolo et al. 2007). The learners should be taught to be respectful of diversity, cultural differences, and the opinions of others. A decision-making process around classroom activities and rules should attempt to include all the learners. The teacher should inculcate an attitude of self-discipline in the learners (Lorenz 2002).

The relationship between the teacher and the learners should be based on the principle of equal treatment for all learners, regardless of their background. It must be a relationship that is fostered by values of respect, genuineness and empathy (Fox 2003).

Teacher-learner relationships are enhanced by effective communication and interaction (Antia 1999). Effective communication is a prerequisite for the development of "social competence", which is the ability to work and interact with others. Language is crucial to communication, but in their interaction with learners, teachers also have to be aware of non-verbal forms of communication such as gestures. All in all, language is important for the development of the learner`s cognitive, social and cultural development (Brown 2002; Conteh 2003).

Language is a medium through which learners learn. In countries such as South Africa, language is still used by some to exclude other races, with schools separating learners according to the language of instruction in the classroom, often under the pretext of mother-tongue teaching and the protection of standards (Chick 2000).

The concept of pastoral care, which is the process of establishing genuine relationships of care with the learner, is pivotal in the development of the learner's self-esteem within the culture of inclusion (Farrell and Ainscow 2002). The learners feel emotionally valued if they are unconditionally accepted by the teacher. Teachers have to orientate the learners towards emotional maturity. The development of the learners' emotional attributes enhances their emotional intelligence. This form of intelligence is the process encompassing the learner's self-awareness, mood control, motivation, the development of empathy, and the ability to manage relationships (Bartolo et al. 2007). Learners should be taught to use their internal locus of control to attribute their successes or failures appropriately without blaming themselves unnecessarily as it could have negative consequences for their sense of identity. A positive self-concept is vital for developing healthy self-esteem. Teachers have to inculcate in their learners a spirit of resilience, which is the capacity to survive, cope with adversity in their lives (Rief and Heimburge 2006). Resilience is promoted by the recognition and appreciation of each individual learner's effort, effective communication and, to a greater extent, the involvement of parents in the selfactualising process of the learner.

Teachers should recognise that learners are different and that every learner brings unique experiences to the classroom. Teachers have to foster a culture of respect for differences and the ability to draw strength from diversity. Stimulating critical thinking broadens the horizon by clarifying misconceptions about cultural differences; therefore teachers should ensure that the learning material responds to the needs of diverse cultures. There should be a positive correlation between the learner's home culture and the classroom (school) culture (Brown 2002).

The analysis of what are thought to be inclusive teaching and an inclusive classroom seems to be based on the notion or the idea of a traditional classroom where there is mono-teaching, with learners homogeneously belonging to the same grade. While there have been efforts to implement inclusion in South African schools, White Paper 6 (DoE 2001) is silent on inclusion within multi-grade classrooms. Besides the attempts to define an inclusive pedagogy within mono-teaching classrooms, little attention has been given to defining inclusive pedagogy within a multi-grade classroom.

\section{Conceptualising Multi-grade Teaching}

Multi-grade teaching refers to teaching more than one grade in the same classroom. This form of teaching differs from mono-grade instruction as aspects such as lesson preparation and assessment have to accommodate learners from 
different grades in the same classroom (Beukes 2006; Taole 2014).

Multi-grade teaching has been used in different countries throughout the world for many years already (Brown 2008). Brown postulates that multi-grade classes are usually established where there are few learners per grade in a school. Brown (2008) further holds that the notion of multi-grade teaching is practised within the epistemological framework of constructivism. Learners participate in their learning and work collaboratively with one another. It is noteworthy that this educational approach has affinities with the notion of outcomes-based education adopted in South Africa during the advent of the new educational dispensation. Multi-grade teaching, however, presents various challenges to teachers, such as their ability to manage a multi-grade classroom, a shortage of appropriate resources, and the complicated nature of planning and lesson presentation. While a number of studies have confirmed the success of multi-grade teaching with regard to the scholastic achievement of learners (Miller 1990) and its advantage to foster social learning among the learners (Brown 2008), hardly any studies have explored the success of multi-grade teaching in an inclusive class.

\section{The Aim of the Study}

In South African rural schools, teachers use multi-grade teaching as a pedagogic practice concurrently with having to implement inclusive teaching. They are therefore confronted with the daunting task of having to define what it means to teach in an inclusive way in the rural context within multi-grade classrooms. As yet, the following question remain unanswered: How can teaching in a multi-graded classroom be made inclusive?

In order to answer this overarching question the following sub-questions were posed:

What is inclusive multi-graded teaching?

Which practices could enhance inclusion in a multi-graded classroom?

\section{Theoretical Framework}

The research on which this article is based adopted a critical realist approach. This approach was developed by Bhaskar (1989) and focuses on the structures, entities and mechanisms that constitute the social world (Burnett
2007). Similar to critical theory, critical realism finds its habitus in the uncompromising position of social reality. A brief summary of critical realism as expounded by Bhaskar follows:

- The world exists independently of our knowledge of it.

- All knowledge is fallible.

- Knowledge is transient (metabletic) and relative to the historical, social and political context;

- Individuals (agents) produce and transform social structures while the structures constrain and shape the individuals (Giddens 1984, 2013).

Critical realism advocates the importance of the relationship between an individual and structure. The medium through which an individual develops occurs within structures, mechanisms and processes which are real. The role of the structure becomes paramount in relation to its members.

Burnett (2007) posits that critical realism views the world as consisting of social realities which are usually independent of us. Individuals have to discover reality through empirical processes and by employing their senses. However, the perceived reality could differ from actual reality in that what is perceived to be real might not be. Burnett (2007) further postulates that there is a causal relationship between an individual and the structure:

The critical realist view of social reality is that individuals reproduce and transform social structures as well as being formed by them, whilst social structures both shape and place constraints on individuals but are also the results of continuous activity by individuals.

What the statement implies is that individuals are influenced by the socio-cultural factors of their society which are embedded within structures. There is an interplay of knowledge between a particular society and its members. Burnett (2007) stresses that the beliefs and knowledge held by any given society might not necessarily be correct as correctness is determined by how communities construct and reconstruct forms of knowledge - a view embedded in social constructivism.

Critical realism assumes that the social realm is influential and that socially constructed beliefs may be manipulated to perpetuate inequality in society. The emphasis is on the interrelationship between individuals and their society, 
which forms the basis for mutual transformation. The current constructions of 'disability' are founded on "fallible" constructions which could, if, challenged, foster the attainment of emancipation.

Critical realism is premised on the notion of a duality of agent and structure. Reality is layered into the following three strata: the domain of real, which includes the actual events generated or caused by specific mechanisms; the domain of actual, which encompasses the underlying generative mechanisms which may or may not be exercised by actors within social reality; and the domain of the empirical, which includes social reality as a world that is observable through the senses. Therefore critical realism creates an appropriate lens to unmask the different layers of reality and expose the underlying mechanisms which may constrain the agency of teachers and learners within a multi-grade classroom.

\section{METHODOLOGY}

The study reported on in this article was (generatively) qualitative and used multiple cases to generate data. Five classes were observed according to a pre-planned schedule and their teachers were interviewed using open-ended questions. Observations and interviews were terminated upon reaching theoretical saturation, that is, when no new knowledge was being generated. The classes were randomly selected from different multi-grade schools in one of the districts in the Free State province.

The process of analysis involved analyzing and interpreting the development data inductively according to the following steps (Laws et al. 2003: 395).

Step 1: Reading and rereading all the data closely. This was done to ensure that researchers were fully conversant with the facts to make the process of analysis more manageable.

Step 2: Drawing up a preliminary list of themes arising from the data. The process involved categorising the data into themes (that is, "coding the data"), assigning labels or texts to all the data collected, and organising raw data into conceptual categories in order to make the data more manageable.

Step 3: Re-reading the data to confirm the themes. By reading the data several times, researchers were able to verify that the interpretations were correct.
Step 4: Linking the themes to quotations and notes. Researchers then wrote themes alongside the quotations and notes as they went through the data to establish interrelationships.

Step 5: Perusing and interpreting the categories of themes. This was done to discover what the data were telling researchers in relation to the objectives of the study.

Step 6: Designing a tool to assist in discerning patterns in the data. In order to triangulate and determine the patterns during data analysis, a spreadsheet was used which gave a summary of the themes. For example, the spreadsheet recorded the title of the theme and quotations from different sets of data.

Step 7: Interpreting the data. During this stage, researchers re-read the quotations and deduced the meaning of each in relation to the others. This resulted in my interpretations, which researchers presented according to each theme.

\section{FINDINGS}

The data analysis generated the following themes:

\section{Communication in a Multi-grade Class}

It was clear that the learners and teacher in a multi-grade class communicated freely and interactively. Asked about the benefit of being in a multi-grade class, one learner replied: "When we are in the class, we can speak to our fellow learners from other grades and ask questions." The learner's response suggests that the learners valued the space provided by a multi-grade setting for them to be able to communicate across the grades.

\section{Collaboration in a Multi-grade Class}

The data showed that learners in a multigrade class, even when not instructed to work together on a specific classroom tasks given by the teacher, collaborated with learners from other grades. One learner remarked: "If I struggle to complete a task provided by the teacher, I normally ask learners in Grade 5 [the learner was in Grade 4] for them to help me." Asked if this was helpful, the learner responded: "Yes, we are able to work together." While the learners were positive about working together, the teacher believed that working together was only encour- 
aged when the task demanded group work and not always. For example, one of the teachers stated: "Learners are allowed to talk to and work with one another when there a group-work task is given, not always." It was clear that, although the learners felt that working together was important, there was a clear restriction imposed on this by the teacher.

\section{Content Integration in a Multi-grade Class}

The data suggested that the way teachers taught the different subjects was such that different topics derived from the work of the various grades. For example, one of the teachers related how the work was selected and presented: "I choose the work for Grade 5, 6, 7 and try to present the work in such a way that [all the] learners in those grades will understand it at their own level of understanding." When asked about the value of being taught content with learners from other grades, one of the learners said: "Because we are all there in the class being taught the same subjects, when we arrive at home we can help one another with [the] homework." The analysis shows that integrating content across different grades forces learners to depend on one another and to cooperate in the learning process.

\section{Socialisation within a Multi-grade Class}

It became clear that learners interacted with their peers from different grades. Although the learners were from different grades, it seemed that sharing a multi-grade class had influenced them to accept and respect one another; for instance, one learner stated: "We all accept that we are one big family regardless of the grade you are in." This sentiment was echoed by one of the other teachers when asked about how being in one class bridged the diversity gap between the learners in the classroom. The teacher said: "Learners are from different families with different socio-economic, ethnic and perhaps cultural backgrounds, but being in a multi-grade class creates a bond between them and they are able to tolerate one another." Furthermore, being in the same class exerted a profound impact on the learners to share resources and space. For instance, one of the learners pointed out: "If I do not have a calculator, I borrow from those in Grade 7 because all of them must have it”. In general, it seems that multi-grade classes foster appropriate socialisation, as well as acceptance and respect for diversity, which is crucial to effective participation in the classroom.

\section{Democratic Classroom Participation}

The data showed that, in a multi-grade class, democratic participation and decision-making are essential. For example, some of the learners indicated that they were able to choose their peers or those whom they wished to work with. For instance, asked about how democratic the activities in the class were, one learner said: "I like it when the teacher allows us to choose people whom I can do classroom tasks with." While the learners were optimistic about their democratic right of choice in the classroom, it appeared that the teachers were not ready to relinquish their authority to make way for other learners to enjoy full democratic decision-making; for example, one teacher lamented that "learners sometimes want to take over; once you allow them, they do not see you; they want to do as they please". While there was an indication that the learners were willing to be involved in decisionmaking in the classroom, it appears that some teachers were not yet fully convinced that it would be appropriate to allow learners to have full rights to make choices and take partial control of some activities in the classroom.

\section{DISCUSSION}

At the beginning of this article the question was asked: How can teaching in a multi-graded classroom be made inclusive? The next section will discuss the findings using the following research questions as a framework and guide: What is inclusive multi-graded teaching? Which practices could enhance inclusion in a multigraded classroom? The themes derived from the research were used to guide the discussion of the findings in order to answer the questions.

\section{Communication in a Multi-grade Class}

Previous studies on inclusion have emphasized the significant of communication in developing practices of inclusion (Antia 1999; Brown 2002; Conteh 2003; Makoelle 2013, 2014). Although most focused on teaching in a classroom with a single grade, this research study, though has demonstrated that inclusion in a 
multi-grade class is also influenced by how effectively communication between the learners and the teacher and between the learners themselves is enhanced. The conclusion is that effective communication is fundamental for inclusion within a multi-grade class.

\section{Collaboration in a Multi-grade Class}

Ainscow and Miles (2010) echoed by Rahaman and Sutherland (2011) supported by Makoelle (2014), indicate that collaboration is crucial for inclusion, in the research study reported on here inclusion was enhanced when the learners in a multi-grade class were permitted to collaborate across grades. This has demonstrated that collaboration at various contexts is crucial and important for inclusion to take place even in a multi-grade class.

\section{Content Integration in a Multi-grade Class}

The aspect of context integration across grades is a phenomenon associated with multigrade teaching. In the research study, the integration of content fostered co-operation on the part of learners across the grades. Indeed, exposure to the same topic of learning content provided a basis for teaming up learners in the lower grades with learners in the senior grades, thus fostering a more inclusive atmosphere for learning.

\section{Socialisation within a Multi-grade Class}

Mastropieri and Scruggs (2001) echoed by Lehohla and Hlalele (2012) have sort to conceptualise an inclusive class as a space from which the learner is socialized while their focus was on mono-grade classes, this study on which this article is based demonstrated that the sharing of space and resources predominated in multigrade classes, and that such sharing had farreaching implications for supporting learners. If all of these resources had not been shared, learning would have been a daunting task. Indeed, the sharing of resources across grades appeared to have had a profound impact on learning, especially in previously disadvantaged classrooms in the South African rural context.

\section{Democratic Classroom Participation}

Democratic atmosphere in an mono-grade inclusive classes has been found to be a prerequisite for inclusive pedagogy (Lorenz 2002; Fox
2003; Bartolo et al. 2007), this study though in a multi-grade class has indicated, that when learners were included in the decision-making process in the classroom, they were likely to participate actively in the classroom activities. Furthermore, this had a profound influence on collaboration and appeared to widen the participation of learners in the classroom. It could be concluded that democratization of class participation is significant for inclusion even in multigrade classes.

\section{CONCLUSION}

While numerous studies on multi-grade classrooms have been conducted across the globe, the study on which this article is based attempted to conceptualise inclusive pedagogy within a multi-grade classroom and in disadvantaged rural classrooms in the South African context in particular. Although the study had been conducted on a small scale, the findings make a significant contribution to understanding the notion an inclusive pedagogy within multi-grade classrooms in South Africa.

\section{RECOMMENDATIONS}

It is therefore recommended that teachers in a multi-grade class should encourage intergrade communication among the learners as it was beneficial to learners and fostered classroom community learning. Teachers should therefore allow intergrade collaboration because this would widen participation for all learners in the classroom. It is therefore crucial for teachers, while integrating content in their teaching, to encourage integrated learning because this will have positive scaffolding consequences for all learners. It therefore stands to reason that learners in multi-grade classrooms should be socialised towards communal resource utilisation to accommodate those facing the challenge of resource shortages. It can therefore be concluded that teachers in multi-grade classrooms should encourage learner involvement in the decisionmaking process, particularly about what is being taught and how it can be learned.

\section{REFERENCES}

Ainscow M 1999. Understanding the Development of Inclusive Schools. London:Routledge Falmer. 
Ainscow M 2013. From Special Education to Effective Schools for All: Widening the Agenda. In: Lani F. Sage Handbook of Special Education. $2^{\text {nd }}$ Edition. London: Sage Publications.

Ainscow M, Booth T 2002. Index of Inclusion. Bristol: Centre for Studies in Inclusive Education (CSIE).

Antia SD 1999. The role of special educators and classroom teachers in an inclusive school.Journal of Deaf Studies and Deaf Education, 4: 203-214.

Bartolo PA, Janik J, Janikova V, Hofsass T, Koinzer P, Vilkiene V, Calleja C, Cefai C, Chetcuti D, Ale P, Mollous A, Wetso G, Humphrey N, Conteh J 2003. Succeeding in Diversity, Culture, Language and Learning in Primary Classrooms. London: Trentham Book.

Bartolo PA, Janik J, Janikova V, Hofsass T, Koinzer P, Vilkiene V, Calleja C, Cefai C, Chetcuti D, Ale P, Mollous A, Wetso G, Humphrey N 2007. Responding to Student Diversity Teacher Handbook. Amsterdam: Faculty of Education, University of Malta.

Beukes CG 2006. Managing the Effects of Multi-grade Teaching on Learner Performance in Namibia. Dissertation. Magister Education. Johannesburg: University of Johannesburg.

Bhaskar R 1989. Reclaiming Reality: A Critical Introduction to Contemporary Philosophy. London: Verso.

Brown BA 2008. Multi- grade Teaching: A Review of Selected Literature and Implication forEducator Education and Training in South Africa. East London: University of Fort Hare.

Brown EL 2002. Mrs Boyd's Fifth-grade Inclusive Classroom: A Study of Multicultural Teaching Strategies. London: Sage.

Burnett NB 2007. Critical realism: The required philosophical compass for inclusion? Australian Association of Research in Education: Research Impacts: Proving or Improving? 25 $5^{\text {th }}-29^{\text {th }}$ November, 2007, Fremantle, Western Australia.

Cheminias R 2004. How to Create an Inclusive Classroom. London: David Fulton.

Corbett J 2001. Teaching approaches which support inclusive education: A connective pedagogy. British Journal of Special Education, 28(2): 55-59.

Department of Education 2001. Education White Paper 6: Building an Inclusive Education and Training and System. Pretoria.

Dyson A, Millward A 2000. Schools and Special Needs: Issues of Innovation and Inclusion. London: Paul Chapman.

Farrell P, Ainscow M 2002. Making Special Education Inclusive. London: David Fulton.

Florian L (Ed.) 2007. The Sage Handbook of Special Education. London: Sage.

Florian L, Linklater H 2010. Preparing Teachers for Inclusive Education: Using Inclusive Pedagogy to Enhance Teaching and Learning for All. London: Routledge, Taylor and Francis Group.

Fox M 2003. Including Children 3-11 with Physical Disabilities: Practical Guidance for Mainstream Schools. London: David Fulton.

Giddens A 2013. The Constitution of Society: Outline of the Theory of Structuration. California: John Wiley and Sons.

Hart S 1996. Beyond Special Needs: Enhancing Children's Learning through Innovative Thinking. London: Paul Chapman.

Laws S, Harper C, Marcus R 2003. Research for Development. London: Sage.
Lehohla M, Hlalele D 2012. Inclusive classrooms: An ecosystemic perspective. Journal of Human Ecology, 37(3): 189-201.

Lorenz S 2002. First Steps to Inclusion. London: David Fulton.

Makoelle T M 2014. Changing teacher beliefs and attitudes towards inclusion in South Africa: Lessons from collaborative action research. Journal of Social Sciences, 38(2): 125-134.

Makoelle TM 2013. Inclusive Pedagogy in Context: A South African Perspective: Saarbrücken: Lambert Academic Publishing.

Makoelle T M 2013. Exploring Teaching Practices that are Effective in Promoting Inclusion inSouth African Secondary Schools. PhD Thesis, Unpublished. Manchester: University ofManchester.

Mastropieri MA, Scruggs TE 2001. Promoting inclusion in secondary classrooms. Learning Disability Quarterly, 24(4): 265-274.

Miles S, Ainscow M 2010. Responding to Diversity in Schools: An Inquiry-based Approach. London: Taylor and Francis.

Miller B A 1990. A review of the quantitative research on multigrade instruction. Research in Rural Education, 7(1): 1-8.

Night T 1999. Inclusive Education and Educational Theory: Inclusive for What? Paper Delivered at the British Research Association Conference, 2-5 September, University of Sussex, Brighton.

Nilholm C, Alm B 2010. An inclusive classroom: A case study of inclusiveness, teacher strategies and children experiences. European Journal of Special Needs Education, 25(3): 239-252.

Nind M, Sheehy K 2004. Making it Happen: Inclusive Education, Learning from Each Other. Milton Keynes: Open University Press.

Rahaman M, Sutherland D 2011. Inclusive Education Practice for Secondary School: Students with Disabilities in Bangladesh. Madrid: IATED.

Rief S, Heimburge JA 2006. How to Reach and Teach all Children in the Inclusive Classroom: Practical strategies, lessons and activities. $2^{\text {nd }}$ Edition. London: Jossey-Bass.

Skidmore D 2004. Inclusion the Dynamic of School Development. New York: Open University Press.

Stainback S, Stainback W 1992. Facilitating Curriculum Considerations in Inclusive Classrooms: $\mathrm{Fa}$ cilitating Learning for All Students. Baltimore, MD: Paul H. Brooks.

Taole MJ 2014. Quality basic education for all: Challenges in multi-grade teaching in rural schools. Mediterranean Journal of Social Sciences, 5(1): 531536.

Tembo A, Ainscow M 2001. Teachers'Attitudes and Beliefs towards the Inclusion of Students with Disabilities into the General Primary Education Classrooms in Zambia. Manchester:University of Manchester.

Trent SC, Artiles AJ, Englert CS 1998. From deficit thinking to social constructivism: A review of theory, research, and practice in special education. Review of Research in Education, 23: 277-307.

UNESCO 2001. Understanding and Responding to Children's Needs in Inclusive Classrooms. Paris.

Volts DL, Sims MJ, Nelson BP 2010. Connecting Teachers, Students and Standards: Strategies for Success in Diverse and Inclusive Classrooms. Alexandria: ASCD. 